malaria, tuberculosis and leprosy, leishmaniasis, trypanosomiasis and amoebiasis. There is a great deal of information about chemotherapy crowded into this small book, much of it not readily accessible elsewhere, and although it will almost certainly prove far too detailed for the ordinary lay reader, there must be many medical men who will derive great pleasure and profit from reading it.

\section{RECENT ADVANCES IN CHEMOTHERAPY}

\section{Vol. III-Antibiotics}

By F. C. O. Valentine, F.R.C.P. and R. A. Shooter, M.A., M.D. 3rd Edition. Pp. viii + 292, with 7 illustrations. London: J. \& A. Churchill, Ltd. $1954 . \quad 27 \mathrm{~s} 6 \mathrm{~d}$.

This volume is one of those forming the third edition of the late Dr. G. M. Findlay's book, of which the previous edition appeared in 1939 . While incorporating much of his material, the authors have therefore written an entirely new book dealing with an era of therapeutics that hardly seemed remotely possible 15 years ago. Fewer than 30 of the several hundred references are to papers published more than ten years ago. On the other hand, the very large number listed that appeared in 1953 testifies to the efforts made by the authors to summarize the immense and rapidly growing literature. This is an admirable book concise and authoritative, giving chapter and verse for much advice on therapy that must occasionally be controversial when one treatment may be superseded by another almost before its validity can be firmly established. A reasonable balance is struck between the laboratory and the ward. Two suggestions might be worth following in the next edition-the whole subject of the prophylaxis of infections might be dealt with in a separate section, while there is a need for a really vigorous chapter entitled 'The Dangers and Complications of Antibiotic 'Therapy.'

\section{THE HAEMOLYTIC ANAEMIAS, CONGENITAL AND ACQUIRED}

By J. V. DAcie, M.D., M.R.C.P. Pp. $x+525$, with 98 illustrations. London: J. \& A. Churchill, Ltd. 1954. 50s.

This book on the haemolytic anaemias is a comprehensive review by a haematologist of international reputation who has made a special study of this subject over a period of many years. In addition to reviewing the world literature Dr. Dacie has drawn extensively on his own clinical material and has included numerous case histories. The book opens with a chapter on the general features of abnormal haemolysis and the methods used in investigation. Thereafter follow detailed accounts of the different haemolytic anaemias. The last chapter describes in detail the techniques used in the investigation of these conditions. Altogether this is a most satisfying book that should undoubtedly be in the hands of every clinical pathologist, and indeed, of anyone interested in diseases of the blood. The reviewer has found little to criticise. Indeed, the only comment he would like to make is that he would like to have seen more details of the newer methods of estimating erythrocyte survival time. Dr. Dacie has done a service to haematology by writing this very comprehensive review. The book is well produced and adequate $y$ illustrated.

\section{THE ROOTS OF CRIME}

Edited by the late Sir Norwood E4ST, M.D., F.R.C.P. Pp. ix + 18r. London: Butterworth $\&$ Co., Ltd. I 954 . 30 .

This is a fascinating volume of reminiscences, opinions and informative essays by six notable contributors who write of what they know without paying more than a passing glance (or none) at its nominal subject.

He who is at all prepared to have his interest stimulated in crime and its reduction, or in criminals and their treatment, or in the ways and language of psychologists and psychotherapists, or in the current topics of spivs and homosexuals can get the book with confidence. But he must not expect an exhaustive scientific analysis concentrating actually upon the causes of crime.

The production is excellent for general arrange ment and readability: a full list of references follows each chapter; there is a glossary and an index. Short of browsing over the book itself, the best way to judge the nature and quality of its contents is to note the names and qualifications of the individual contributors and the titles under which each writes :

I. 'Legal and Medical Advances in Criminology,' by the late Sir Norwood East, M.D., F.R.C.P., formerly Lecturer on Forensic Psychiatry, Institute of Psychiatry, Maudsley Hospital; formerly H.M. Commissioner of Prisons, Inspector of Retreats under the Inebriate Acts.

2. 'A Psychiatric Approach to the Off ender,' by Desmond Curran, M.B., F.R.C.P., D.P.M., Senior Psychiatrist to St. George's Hospital; Civil Consultant, Psychological Medicine, to the Royal Navy.

3. 'A Clinical Contribution,' by Peter Scott, M.A., M.D., D.P.M., Physician to the Maudsley Hospital; Psychiatrist to L.C.C. Remand Home, Visiting Psychiatrist to H.M. Prison, Brixton.

4. 'Remedial and Educational Psychotherapy During Penal Detention,' by John C. Mackwood, M.C., M.R.C.S., L.R.C.P., Psychotherapist to H.M. Prison, Wormwood Scrubs.

5. The Role of Probation in the Treatment of Offenders,' by W. Clifford, B.Sc.(Econ.), Head of Welfare Department, Cyprus; formerly Probation Officer, Surrey.

6. 'The Magistrate and the Psychiatrist,' by Frank J. Powell, Metropolitan Police Magistrate, Clerkenwell.

B.M. 